\title{
Questão de gênero: A percepção de alunos e ex-alunos de pós-graduação stricto sensu em administração sobre competências gerenciais.
}

\begin{abstract}
Resumo
O objetivo do estudo é verificar a existência de relações entre variáveis demográficas e a percepção quanto ao constructo competências gerenciais. O estudo é de natureza quantitativa, com coleta de dados por meio de questionário construído a partir da revisão do referencial teórico. Foram enviados 227 questionários a alunos e ex-alunos de pós-graduação stricto sensu em administração de uma universidade particular do Estado do Paraná e foram recebidas 130 respostas válidas. Os resultados indicaram haver diferenças estatisticamente significativas entre as percepções de homens e mulheres para a maioria das competências. Outras variáveis demográficas, como idade, escolaridade e experiências funcionais e gerenciais, não se mostraram estatisticamente significativas. A contribuição desta investigação está na confirmação de que homens e mulheres percebem os atributos de competências de maneiras diferentes e nos questionamentos que esta observação implica. Ao revelar que entre as variáveis demográficas pesquisadas é o gênero que mais se correlaciona com a percepção sobre o constructo competências gerencial, abre-se um caminho para debates sobre questões de gênero nas organizações, inclusive quanto aos modelos de competência que têm sido adotados pelas consultorias e organizações estar ou não enviesados em sua constituição e uso. Tal discussão pode ser um início de debates que reconheçam a importância das diferenças entre gêneros e que permitam a compreensão e a articulação dos diferentes significados no processo de sense-making entre homens e mulheres.
\end{abstract}

Palavras-chave: Atributos de Competência, Competências Gerenciais, Análise Quantitativa.

\section{Gender"s issue: Perception of students and ex-students of post-graduate in administration about managerial competences.}

\section{Abstract}

The aim of the study is to verify the existence of relationships between demographic variables and perceptions regarding the construct of managerial competencies. The study is quantitative in nature, with data collection by questionnaire constructed from the literature review. It was sent 227 questionnaires to students and former students of postgraduate studies in management of a private university from Paraná State, and 130 valid responses were received. The results indicate there were statistically significant differences

\footnotetext{
Professor Efetivo da Universidade Federal de Mato Grosso - Campus Universitário de Rondonópolis - Curso de Administração desde 2013. Coordenador da Linha de Pesquisa em Gestão de Pessoas. Profissional com ampla experiência no mercado atuando em diversas áreas e posições executivas em empresas multinacionais com Intensiva atuação internacional em países europeus, latino-americanos e Estados Unidos. Doutorando em Administração pela Pontifícia Universidade Católica do Paraná - Linha de pesquisa em Estratégia na Gestão Pública. Mestre em Administração de Empresas pela Universidade Presbiteriana Mackenzie. Pós-Graduado em Administração pela Unicamp - Fundação Getúlio Vargas (FGVSP). MBA Empresarial pela Fundação Getúlio Vargas (FGVSP). Graduado em Engenharia Industrial Elétrica-Eletrônica pelo CEFET-PR. Certificado Project Manager Professional pelo Project Management Institute - USA.
} 
in perceptions between men and women for most competencies. Other demographic variables, such as age, education, functional and managerial experiences, were considered not statistically significant. The contribution of this research is the confirmation that men and women perceive the attributes of competence in different ways and that observation implies questioning. By revealing that among the demographic variables studied is gender that most closely correlates with the perception of managerial competence, opens a path to debates on gender issues in organizations, including as to the competency models that have been adopted by consultants and organizations may or may not be biased in its constitution and use. Such discussion may be an early debate that recognize the importance of gender differences and allow understanding and articulation of different meanings in the process of sense-making between men and women.

Keywords: Attributes of Competence, Managerial Competencies, Quantitative Analysis.

\section{Introdução}

No contexto contemporâneo a única certeza é de mudança contínua e cada vez mais acelerada. Diante do processo de globalização observam-se alterações nos campos político, econômico, social e organizacional. No âmbito das organizações, além de não haver mais fronteiras e limites comerciais, os processos de internacionalização e as atuações em rede, deflagram agressividade concorrencial e o crescimento na consolidação de empresas por meio de fusões, aquisições, e mecanismos de verticalização e horizontalização estruturais.

Segundo Drucker (2001), as organizações estão em processo de transformação com alterações de sua estrutura hierárquica e gerencial, dos processos decisórios e das formas de execução do trabalho. Esta mudança é necessária tendo em vista a alteração demográfica, a reorientação do centro de gravidade do emprego funcional, manual e administrativo para o trabalhador do conhecimento, pela mudança da economia exigindo das empresas inovações e empreendedorismo, além, e principalmente, pelo progresso e desenvolvimento da tecnologia da informação. A evolução da tecnologia nos últimos anos tem aumentado a capacidade de produção e compartilhamento de dados, e se por um lado pode comoditizar informações, por outro pode propiciar ferramentas para a transformação em conhecimento.

A gestão da força de trabalho nas organizações também está vivenciando uma readequação às mudanças ambientais e ao processo contínuo de transformação. Do modelo clássico de administração de pessoal para os modelos pós-modernos de gestão de pessoas, capital intelectual e talentos sobressai o foco no capital humano como um ativo precioso, na valorização do conhecimento, no uso intensivo de times virtuais e equipes multiculturais, além da necessidade de atendimento às exigências legais, seja por puro cumprimento de cotas, ou por uma nova visão da relevância desse assunto para o alcance dos objetivos organizacionais. Diante dessa complexidade tanto no ambiente externo quanto no próprio ambiente interno, muitas organizações estão estruturando processos de gestão por competências como uma das iniciativas para responder coerentemente às mudanças, atraírem e reterem talentos para alcançarem certa vantagem competitiva e se diferenciarem dos concorrentes.

Entre o conjunto de competências de uma organização, especial atenção é dada às competências gerenciais por serem os gestores considerados elementos essenciais na elaboração, disseminação e condução das estratégias organizacionais. Autores como Robotham e Jubb (1996) indicam a existência de mitos sobre o tema competências e criticam as indefinições sobre o que é competência e questionam se a eficiência gerencial pode ser realmente definida e medida. Para os autores, não há clareza sobre o quão generalizável pode ser o modelo de competência gerencial, como relacionar os planos de treinamento com o desenvolvimento de competências e a consequente obtenção de melhores resultados. 
Independente dessas questões há uma intensificação na utilização de diversos modelos por consultorias e organizações sejam elas públicas ou privadas.

Os conceitos, teorias e práticas presentes na literatura sobre o tema competência em geral e no âmbito das competências gerenciais em particular, surge o interesse desta investigação em procurar preencher a lacuna de verificar a existência de relações entre variáveis demográficas, especialmente gênero, idade, experiência funcional e experiência gerencial e a percepção a respeito do constructo competências gerenciais.

A partir de um questionário elaborado e testado por Cardoso (2009), os dados deste estudo foram coletados junto a uma amostra formada por alunos e ex-alunos de pós-graduação stricto sensu em administração de uma universidade privada do Estado do Paraná. Para o tratamento e análise dos dados foram utilizadas técnicas estatísticas, além de análises fatorial, comparativo entre médias e análise de correlações. Os resultados indicam haver diferenças estatisticamente significativas entre as percepções de homens e mulheres para a maioria das competências, porém variáveis demográficas como idade, escolaridade e experiências funcional e gerencial, não se mostraram estatisticamente significativas. A contribuição desta investigação está na abertura ao debate sobre questões de gênero nas organizações, em geral e quanto aos modelos de competências gerenciais adotados pelas consultorias nas organizações, em particular.

O artigo está dividido em cinco partes: a introdução ora apresentada, a fundamentação teórico-empírica, os procedimentos metodológicos, as análises e discussões dos resultados e as considerações finais que incluem limitações e sugestões de estudos futuros.

\section{Fundamentação teórico-empírica}

Desde a idade média o termo competência é indicativo da faculdade atribuída a alguém para julgar questões sendo utilizado para referendar socialmente a pessoa que é capaz de se pronunciar sobre determinado assunto. Com a revolução industrial e com a concepção Taylorista, o termo passa a ser utilizado indicando pessoas capazes de desempenhar determinado papel ou atividade operacionalmente definida. A partir da década de 1970 diversos autores foram se especializando no tema e propondo definições próprias e vários estudos passaram a ser realizados especialmente por duas correntes principais.

A primeira corrente, constituída por estudiosos britânicos (CHEETHEM; CHIVERS, 1996, 1998) e norte-americanos (McCLELLAND, 1973 e BOYATZIS, 1982), identifica competência como a interação entre conhecimentos, habilidades e atitudes de uma pessoa que a qualifica para a realização de um determinado trabalho. A segunda corrente, representada principalmente por autores franceses (Le BOTERF, 1999 e ZARIFIAN, 1999), entende competência como a entrega de valor pelo indivíduo em um contexto profissional.

Em um dos primeiros trabalhos, McClelland (1973) desenvolveu uma técnica denominada entrevista de comportamento eventual que consistia de perguntas abertas situacionais. Os entrevistados eram solicitados a contar os detalhes relativos a um determinado evento, suas ações, os resultados alcançados, como a pessoa se sentiu e com isso objetivava predizer quais dos candidatos teriam mais possibilidades de desempenhar um papel específico. Para o autor, competência está associada à sensibilidade ao contexto. Boyatzis (1982) propôs um modelo integrando as demandas do trabalho, o ambiente organizacional onde o trabalho é realizado e as competências do indivíduo. Segundo o autor, competência representa a capacidade do indivíduo aplicada no contexto do trabalho e que produz uma ação efetiva.

A colaboração europeia amplia os conceitos propostos pela escola americana incluindo novas variáveis para a definição do conceito de competência. Segundo Le Boterf (1999, p. 48), "o profissional competente não é aquele que possui conhecimentos ou habilidades, mas 
aquele que sabe mobilizá-los em um contexto profissional". O bom profissional é aquele que sabe dominar uma técnica e executá-la bem mesmo em um contexto de competitividade e de estresse. São duas as contribuições relevantes, a primeira é que a competência só se realiza na ação, ou seja, quando de fato acontece e a segunda é que esta ação, na prática, acontece sob a influência de uma determinada situação.

Para Le Boterf (1999), a competência do profissional é identificada no saber administrar uma situação profissional complexa, envolvendo acontecimentos, contingências e processos inerentes às características objetivas de determinada situação ou problema em que a dificuldade se refere às capacidades do sujeito para enfrentar tal situação navegando na complexidade, baseando-se em regras e objetivos definidos. O modelo de seis aspectos para desenvolvimento das competências apresentado por Le Boterf (1999), conforme Figura 1, inclui:

1. Saber agir com pertinência: Saber agir não se reduz ao saber fazer, deve ir além do prescrito, encarar o imprevisto e coordenar ações com vistas a um objetivo que faz sentido. É necessário antecipar os incidentes, tratá-los e aprender com eles, pois saber agir é saber interpretar e as competências são reconhecidas por sua inteligência prática das situações (saber e compreender) considerando "prescrições" e "especificações", além de que saber agir supõem saber julgar e às vezes não agir supondo vontade (ação com interesse em agir).

2. Saber mobilizar em um contexto: é saber mobilizar capacidades e conhecimentos de modo pertinente e no momento oportuno diante de uma situação de trabalho. Deve saber mobilizar na hora certa não somente os próprios conhecimentos e habilidades, mas também da rede de profissionais, pois o profissional não é competente sozinho - uso das múltiplas sinapses sociais - a competência é individual e social ao mesmo tempo. Além disso, saber combinar também é saber improvisar diante do imprevisto possibilitando a geração de oportunidades inovadoras. Saber mobilizar passa pelo saber combinar e pelo saber transformar.

3. Saber transpor: é a capacidade de aprender e de se adaptar, competência profissional é um roteiro que serve para agir em uma pluralidade de contextos e que receberá ajustes a cada nova solicitação fazendo uso do processo de generalização ou modelização.

4. Saber aprender e saber aprender a aprender: o profissional deve saber tirar as lições das experiências (aprendizado), fazendo de sua prática profissional uma oportunidade de criação do saber e do uso do tempo para aprendizagem e auto-realização.

5. Saber envolver-se: o profissional não pode se esconder atrás de instruções e dos procedimentos. É preciso querer agir para poder agir, o profissional "habita" sua área de competência e a incorpora, pois é preciso ter coragem e assumir riscos.

6. Exigência de reconhecimento: toda competência para existir socialmente supõe a intervenção do julgamento de terceiros. Julga-se pela eficácia, conformidade ou pela "beleza". Julgamentos baseados em competências "objetivas" são mais facilmente mensuráveis. O talento é competência (ex.: música, artes plásticas, poesia) e é reconhecido por meio da originalidade, engenhosidade e da criatividade. 
Figura 1- Modelo de 6 aspectos para desenvolvimento das competências.

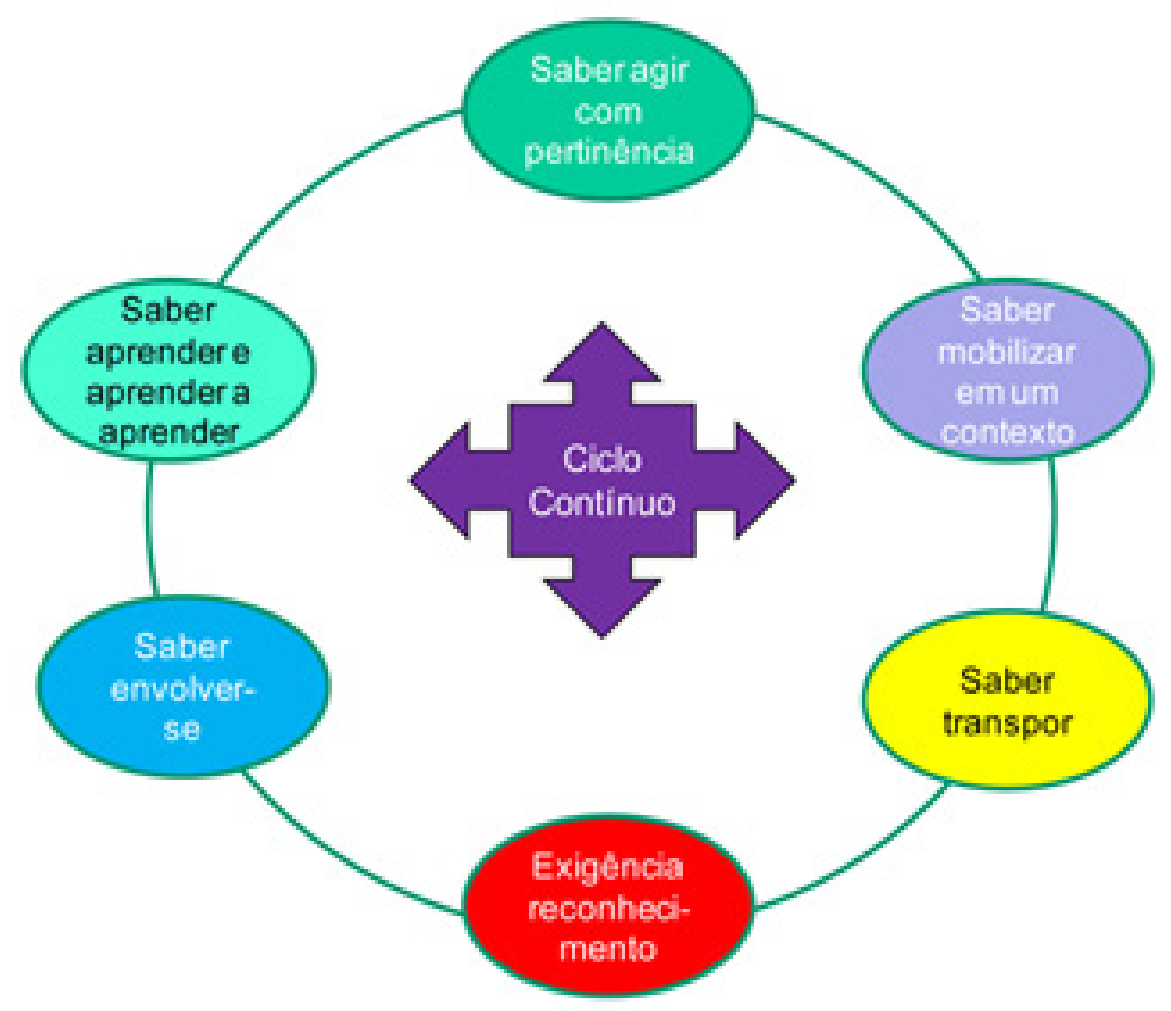

Fonte. o autor (2013) baseado em Le Boterf (1999)

"O retorno do trabalho à competência do indivíduo que o exerce coloca, simultaneamente, a variabilidade e a 'evolutibilidade' das próprias ações profissionais, em razão não unicamente da variabilidade das situações, mas também do entendimento que o indivíduo e a rede de trabalho na qual está inserido podem ter das situações profissionais em dado momento" (ZARIFIAN, 1999, p. 56).

Zarifian (1999) entende que o indivíduo é agente e determina por meio do seu entendimento e compreensão qual o sentido e a dimensão do seu trabalho. Ambos os autores (ZARIFIAN, 1999 e Le BOTERF, 1999) identificam o contexto ou a situação como um elemento importante na análise da competência. A relação entre ambiente de trabalho, o posicionamento do agente executor da atividade, a disponibilidade de informações e as capacidades mentais, cognitivas e afetivas é que o levam a uma interpretação diferente da mesma realidade. Por isso a perspectiva do indivíduo é um diferencial. Outro ponto de concordância entre estes autores é que o profissional competente é aquele que sabe selecionar os elementos necessários no repertório de recursos, apesar de suas heterogeneidades e multiplicidades, e de forma consciente trabalhá-los para realizar uma atividade profissional alinhada com os objetivos da organização.

Entre os autores brasileiros, Carbone (2006, p. 42) indica que, competência é materializada pelo "desempenho expresso pela pessoa em determinado contexto, em termos de comportamentos e realizações decorrentes da mobilização e aplicação de conhecimentos, habilidades e atitudes no trabalho". O autor propõe entender competências humanas como combinações sinérgicas de conhecimentos, habilidades e atitudes, expressas pelo desempenho profissional dentro de determinado contexto organizacional, que agregam valor às pessoas e organizações. Para Dutra (2001) uma pessoa é competente quando, a partir das suas capacidades, entrega e agrega valor a sua organização, a ele próprio e à sociedade em 
que vive. A questão de agregar valor ou produzir algum serviço ou atividade de valor deve ser reconhecida por terceiros, membros da organização, sociedade e pelo próprio indivíduo que a produz ou executa tal como uma auto-realização. Ruas (2005, p. 52) inter-relaciona ação, capacidades humanas, recursos e contexto e propõe um conceito de competência em que "a ação consequente é aquela que mobiliza, integra e prioriza recursos segundo as condições da situação ou contexto, estabelece a capacidade de flexibilidade e adaptação como um de seus elementos essenciais". A combinação eficiente dos recursos, influenciada pelas condições de cada situação ou evento, são ingredientes à concretização do trabalho e o valor gerado pelo resultado desta ação determina a competência.

Uma categorização das competências em uma organização as classifica em essenciais, coletivas e individuais. Quanto às competências gerenciais, contidas no conjunto de competências individuais, Le Boterf (2003, p. 52) indica que o bom gestor não é aquele que aplica em toda circunstância o mesmo comportamento, mas sim é aquele que sabe modular sua estratégia de gerenciamento em função das situações que encontra. Para o autor "a plasticidade está no coração da competência [...] não é uma constante".

Um aspecto relevante nos estudos sobre competência é quanto a sua forma de mensuração. Competência é abstrato o que torna seu estudo e mensuração atividades complexas. McLagan (1997) indica que uma das formas de se definir competência seria por meio de uma coleção de atributos observáveis na prática que pudessem ser avaliados, tornando o conceito abstrato em algo concreto. Zarifian (1999) propõe que é possível construir referências de competências tendo por base categorias de situações, mas menciona a dificuldade de se definir completamente a dimensão de evento das situações. Para Carbone (2006, p. 56) "competências são mais bem descritas por meio de atributos de comportamentos observáveis na prática no ambiente de trabalho e que são passíveis de mensuração [...] desempenho representa uma expressão, uma manifestação da competência".

O Modelo de gestão e aprendizagem proposto por Kolb (1997) e apresentado na Figura 2, estabelece quatro etapas de um processo cíclico: (1) Experiência concreta; (2) Observações e reflexões; (3) Formação de conceitos abstratos e generalizados e (4) Testes de implicações dos conceitos em novas situações. Segundo o autor, é possível compreender como o indivíduo utiliza da sua experiência os conceitos, as regras e os princípios como norteadores nas ações em situações novas e como ele modifica estas práticas para melhorar a eficácia (torna-se mais competente). Conforme Winterton e Winterton (1999) o desenvolvimento de competências depende mais de critérios qualitativos delineados pela interação entre aprendizado cognitivo e emocional, dos estágios de carreira e das diferentes formas de aprendizado ocupacionais. As dimensões tempo e espaço são fundamentais no desenvolvimento de competências coletivas, o tempo é elemento que determina experiência, conhecimento tácito e experiência prática e o espaço, constituído de ambiente e contexto, a mais importante dimensão da competência interpessoal, onde acontece a interação.

Para Freitas e Brandão (2005) há um vínculo entre os conceitos de competência e aprendizagem, em que a aprendizagem representa o processo pelo qual se adquire a competência. Sobre a etapa de avaliação de competências, Brandão e Guimarães (2001) discutem os pontos de convergências e divergências entre modelos de gestão por competências e de avaliação de desempenho. Para os autores, pelo caráter de complementaridade e interdependência é necessária a integração em um único modelo de gestão as atividades de planejamento, acompanhamento e avaliação de desempenho, a partir de um diagnóstico das competências da organização. A etapa de avaliação se utiliza da prática de feedback para descrever a atuação da pessoa em relação às competências que são esperadas, oferecendo a oportunidade de correção de rumo e delineando das trilhas de aprendizagens definidas como caminhos alternativos e flexíveis para o desenvolvimento das pessoas (FREITAS, 2002).

A literatura aponta algumas dificuldades quanto ao uso de modelos de gestão por 


\section{PUC-SP}

competências. Gramigna (2007) cita os principais problemas relacionados à aceitação e ao comprometimento com o modelo. Para o autor as principais dificuldades são a falta de adesão da alta direção, resistência e descrença por parte dos gerentes e colaboradores; os problemas técnicos, com mapeamento inadequado de competências e perfis, avaliação inadequada, falta de agilidade na tomada de decisões, ausência de um sistema de informação adequado às necessidades demandadas; problemas de planejamento, como a descontinuidade das ações, implantação de forma desordenada, falta de gestão da mudança; ou problemas culturais, como a predominância de estilo gerencial centralizador, dos jogos de poder e o costume de agir de maneira reativa, ao invés de proativa.

No ambiente organizacional os gestores enfrentam novos desafios e situações e fazem uso das experiências anteriores, dos resultados produzidos na solução de outros problemas, dos aprendizados passados para agir e tomar suas decisões. Este processo cíclico de aprendizagem e desenvolvimento depende muito mais da riqueza e variedade das experiências vividas, do poder de reflexão e concepção de conceitos do que do tempo de atuação em uma determinada área. Por isso Ruas (2005) alerta que, apesar da dimensão competência individual, e gerencial por estar nela incluída, ser a mais conhecida e difundida, observações empíricas têm mostrado que a noção de competência individual carrega consigo uma grande heterogeneidade de percepções e conceitos nos ambientes empresariais.

Figura 2. A gestão e o processo de aprendizagem

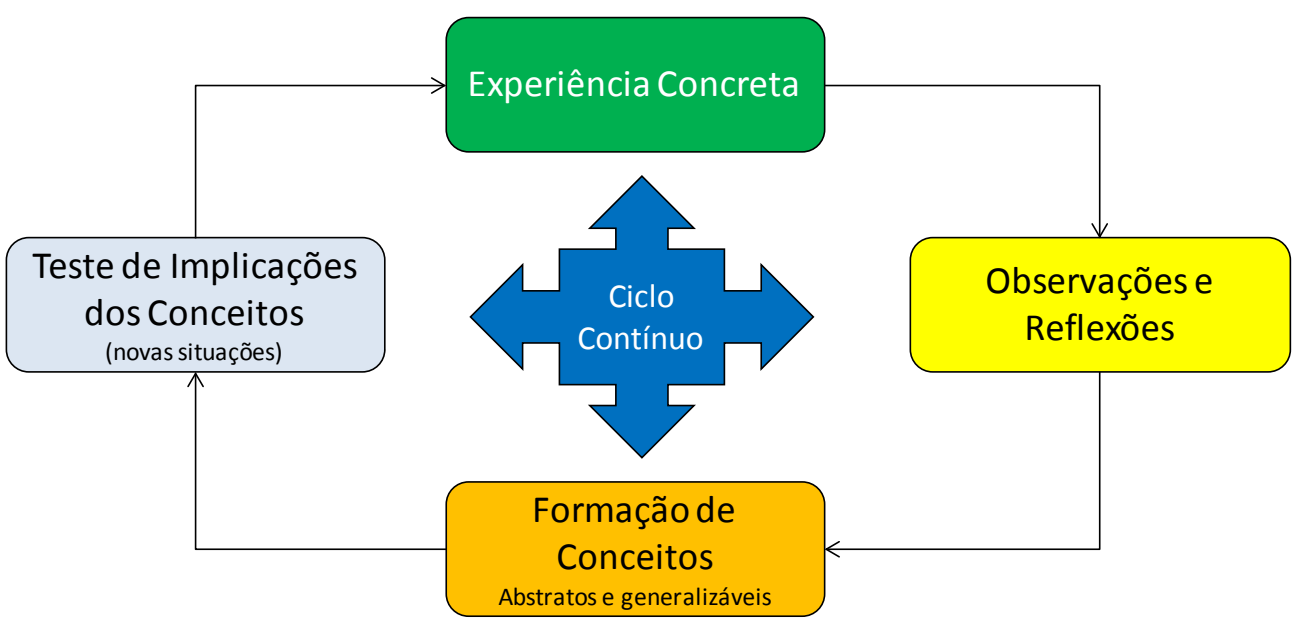

Fonte: KOLB, D. A. A gestão e o processo de aprendizagem. In: STARKEY, K. (org.) Como as organizações aprendem - relatos do sucesso das grandes empresas. São Paulo: Futura, pp. 321-341, 1997. Adaptado pelo autor.

O artigo de McGegor e Tweed (2001) aborda o tema competências considerando variáveis demográficas. Os autores utilizaram uma tipologia de 54 competências gerenciais em uma pesquisa com 363 empresários e gerentes de empresas de manufatura da Nova Zelândia tentando identificar características que individualizassem percepções de homens e mulheres. A análise dos dados indicou que os atributos de competências utilizados no estudo representavam as competências gerenciais para ambos os sexos, demonstrando a efetividade da lista de atributos e indicando algumas diferenças estaticamente significativas entre as percepções de homens e mulheres.

Marshall (1995) critica as pesquisas sobre gerenciamento relacionadas a gênero, pois de 
acordo com a autora as mesmas têm se tornado saturadas com a influência das idealizações masculinizadas. O poder do masculino como norma significa que as mulheres no início de carreira procuram provar sua competência para ganhar igualdade junto aos homens. Mulheres podem ter estilos de liderança, motivações para o trabalho e aspirações de carreira semelhante aos homens, mesmo assim nem sempre são consideradas como gerentes legítimas. A tendência mais recente na teorização sugere que muitas mulheres possuem estilos de gestão mais interativa do que os colegas do gênero masculino e esta tendência é moldada pelo debate semelhança-diferença. O caminho da argumentação é provar que mulheres, por vezes, são diferentes dos homens e defender a igualdade de direitos de serem diferentes e a legitimidade dessas diferenças. Porém, indica a autora que há um perigo, de que as mulheres sejam identificadas com papeis colaborativos, mas pouco valorizadas nos níveis organizacionais. $O$ resultado seria certa harmonização dos talentos da força de trabalho diversificada, mas com posições estratégicas restritas aos homens. Contudo, há sinais de que a próxima onda de teorização pode muito bem ser um reforço do modelo 'andrógina' gerencial, defendendo uma apreciação e mistura de talentos previamente identificados como "masculino" e "feminino".

A autora argumenta que muitos entendimentos no âmbito organizacional e que são considerados incontestáveis foram fundados pela dominância histórica dos homens. Segundo ela, pesquisadores enfrentam desafios sobre como lidar com as diferenças aparentes entre homens e mulheres de forma ampla ou especificamente como parte de um grupo social definido. Diferenças tais como, homens são mais propensos a se preocupar com questões de hierarquia e status e mulheres com questões de igualdade de participação e relacionamento, são exemplos indicados por Marshall (1995) como algumas das diferenças identificadas. A difusão contínua do masculino como norma faz com que alguns territórios se tornem perigosos para serem explorados, apresentando contínuos desafios para os pesquisadores de fenômenos relacionados ao gênero. Pesquisadores de gênero, então, necessitam do recurso de teorias complexas e sutis sobre mudança organizacional e social capazes de apreciar a resiliência, a dinâmica sistêmica, os processos de poder e as suas relações.

O trabalho realizado por Cardoso (2009) com 56 gestores de uma organização, identificou um conjunto de 10 competências gerenciais subdivididas em 36 atributos de competências. $O$ estudo buscou identificar a diferença de percepção em contextos de estabilidade e mudança organizacional. Os resultados indicam haver diferenças estatisticamente significativas entre as percepções de gestores em diferentes contextos (estabilidade e mudança), de que o nível de escolaridade está relacionado com a percepção sobre os atributos de competências e de que o fator tempo de experiência gerencial não teria relação estatisticamente significativa com a percepção dos gestores sobre suas competências.

A partir da revisão dos estudos anteriores, especialmente utilizando-se do questionário elaborado por Cardoso (2009) e da formulação do objetivo desta investigação que é verificar a existência de relações entre variáveis demográficas e a percepção quanto ao constructo competências gerenciais, foram delineados os procedimentos metodológicos.

\section{Procedimentos metodológicos}

O método de pesquisa foi o quantitativo com coleta de dados via questionário eletrônico e tratamento dos dados utilizando-se de modelos estatísticos com o emprego de análise fatorial, comparativo entre médias e análise de correlação. O público de interesse foi de alunos e exalunos dos cursos de mestrado e doutorado em administração de uma universidade privada paranaense, totalizando 227 pessoas.

Baseado no estudo de Cardoso (2009) foi elaborado um questionário utilizando o software Qualtrics e cuja validade interna foi testada, previamente, com 3 membros do público alvo da pesquisa, como uma forma de verificação do entendimento das questões, 


\section{PUC-SP}

de possíveis dificuldades e dúvidas no preenchimento. O questionário foi enviado a todos os 227 alunos e ex-alunos solicitando aos respondentes que indicassem a percepção sobre cada um dos 36 atributos de competências por meio de uma escala Likert de 5 pontos (sendo 5 como extremamente importante, 4 como muito importante, 3 como importante, 2 como pouco importante e 1 como nada importante). Foram recebidas 130 respostas completas (taxa de retorno de $57 \%$ ) e todas foram consideradas válidas. Após a consolidação dos dados utilizou-se o software SPSS (statistical package of social sciences) para tratamento e análise dos dados.

Segundo Hair (2006, p. 388), a análise fatorial "é uma técnica estatística multivariada que pode sintetizar as informações de um grande número de variáveis em um número muito menor de variáveis ou fatores". Esta técnica é bastante útil para descobrir relações desconhecidas ou latentes entre variáveis e por meio do agrupamento de variáveis em fatores simplifica a compreensão dos dados. De acordo com o autor, há a necessidade de se obter um número de observações de pelo menos 5 vezes o número de variáveis do modelo. Este aspecto limitaria a aplicação da análise fatorial ao conjunto total de variáveis formadas por 36 atributos tendo em vista o número de 130 respondentes. A estratégia adotada neste estudo foi a de rodar uma análise fatorial com a utilização de rotação dos fatores para buscar reduzir a quantidade de itens propostos por Cardoso (2009) independente das categorias de competências identificadas no modelo. A análise fatorial considerou o uso do coeficiente KMO (índice de Kaiser, Meyer, Olkin), Bartlett's Test of Sphericity e anti-image para a matriz de correlação, fator de extração com Eigenvalues acima de 1 e rotação varimax (FIELD, 2009). Outra ferramenta estatística utilizada foi a análise de correlação. A correlação é uma medida do relacionamento linear entre duas variáveis e indica qual a força desta relação. O delineamento da pesquisa está sumarizado na Figura 3.

Figura 3. Delineamento das etapas da Pesquisa
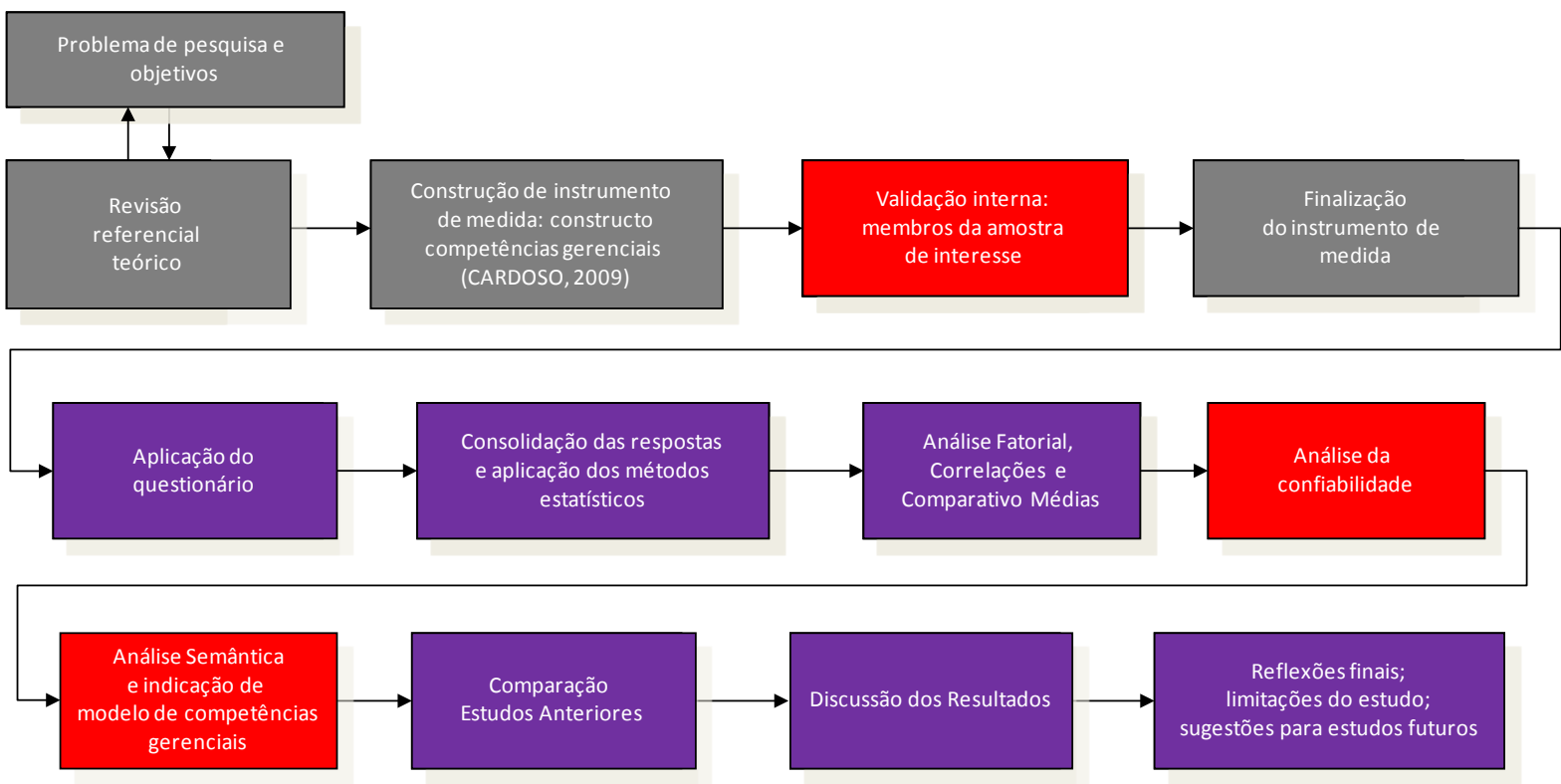

Definição do problema de pesquisa até a identificação do constructo

Critérios de qualidade: validação interna, confiabilidade e análise semântica

Processo de pesquisa: coleta, análise dos dados, discussões e reflexões finais

Fonte: o autor, 2013. 


\section{Apresentação e análise dos dados}

A Tabela 1 apresenta os dados da estatística descritiva que caracteriza demograficamente os respondentes da pesquisa. Dos 130 respondentes, 49 são mulheres, 81 homens e com idade média aproximada de 33 e 39 anos, respectivamente.

Tabela1 - Dados demográficos dos respondentes

\begin{tabular}{|c|c|c|c|c|c|c|c|}
\hline Gênero & Respondentes & Estatisticas & Idade & Respondentes & Experiência & Respondentes & Experiência Gerencial \\
\hline \multirow{5}{*}{ Mulher } & \multirow{5}{*}{49} & Média & 32,53 & \multirow{5}{*}{46} & 13,17 & \multirow{5}{*}{28} & 4,79 \\
\hline & & Mediana & 32,00 & & 13,00 & & 3,50 \\
\hline & & Desvio Padrào & 6,61 & & 6,16 & & 3,63 \\
\hline & & Minimo & 21,00 & & 3,00 & &, 50 \\
\hline & & Máximo & 52,00 & & 26,00 & & 13,00 \\
\hline \multirow{5}{*}{ Homem } & \multirow{5}{*}{81} & Média & 38,86 & \multirow{5}{*}{79} & 17,75 & \multirow{5}{*}{72} & 10,68 \\
\hline & & Mediana & 38,00 & & 17,00 & & 10,00 \\
\hline & & Desvio Padrão & 9,03 & & 8,72 & & 7,51 \\
\hline & & Minimo & 22,00 & & 1,00 & & 2,00 \\
\hline & & Máximo & 56,00 & & 38,00 & & 34,00 \\
\hline Total & 130 & & & 125 & & 100 & \\
\hline$\%$ & $100 \%$ & & & $96 \%$ & & $77 \%$ & \\
\hline
\end{tabular}

Nota. Fonte: o autor, 2013.

Do total de respondentes, $96 \%$ possuem alguma experiência profissional sendo que as 46 mulheres apresentam média de 13 anos de experiência profissional enquanto os 79 homens possuem em média quase 18 anos de experiência profissional. Quanto à experiência gerencial, $77 \%$ dos respondentes indicaram possuir, sendo 28 mulheres (ou $57 \%$ ) e 72 homens (ou 91\%), indicando médias de experiência gerencial de 5 e 11 anos, respectivamente.

Após uma primeira análise fatorial foi possível identificar itens com baixa comunalidade e reduzir a quantidade de atributos para um total de 28 itens. O resultado da segunda análise fatorial, após a redução de 8 itens, apresentou valores de $\mathrm{KMO}=0,862$, variância explicada de 60,79\% com identificação de 7 fatores e com alfa de Cronbach variando entre 0,624 e 0,713. Tendo em vista a eliminação de 8 itens e a redistribuição dos itens remanescentes entre os 7 fatores foi necessária uma readequação da nomenclatura das nomes dados às competências relacionadas com cada um dos fatores. Para esta etapa foi utilizado um processo de análise semântica entre especialistas e estudiosos do tema competência e com membros da amostra participante da pesquisa. Os resultados estão indicados na Figura 4. Após a validação da nova nomenclatura de cada um dos 7 fatores, foi utilizado o método Anderson-Rubin para obtenção dos escores dos fatores de forma a propiciar o comparativo entre as percepções de homens e mulheres sobre o constructo competências gerenciais e a consequente análise dos resultados.

Considerando a redistribuição de atributos identificados na Figura 4, foi verificada a distribuição dos escores dos fatores quanto aos aspectos de normalidade da distribuição (testes de Kolmogorov-Smirnov) e homogeneidade da variância (estatística de Levene). Os dados estão dispostos na Tabela 2 
Figura 4 - Resultados das análises fatoriais e seus indicadores.

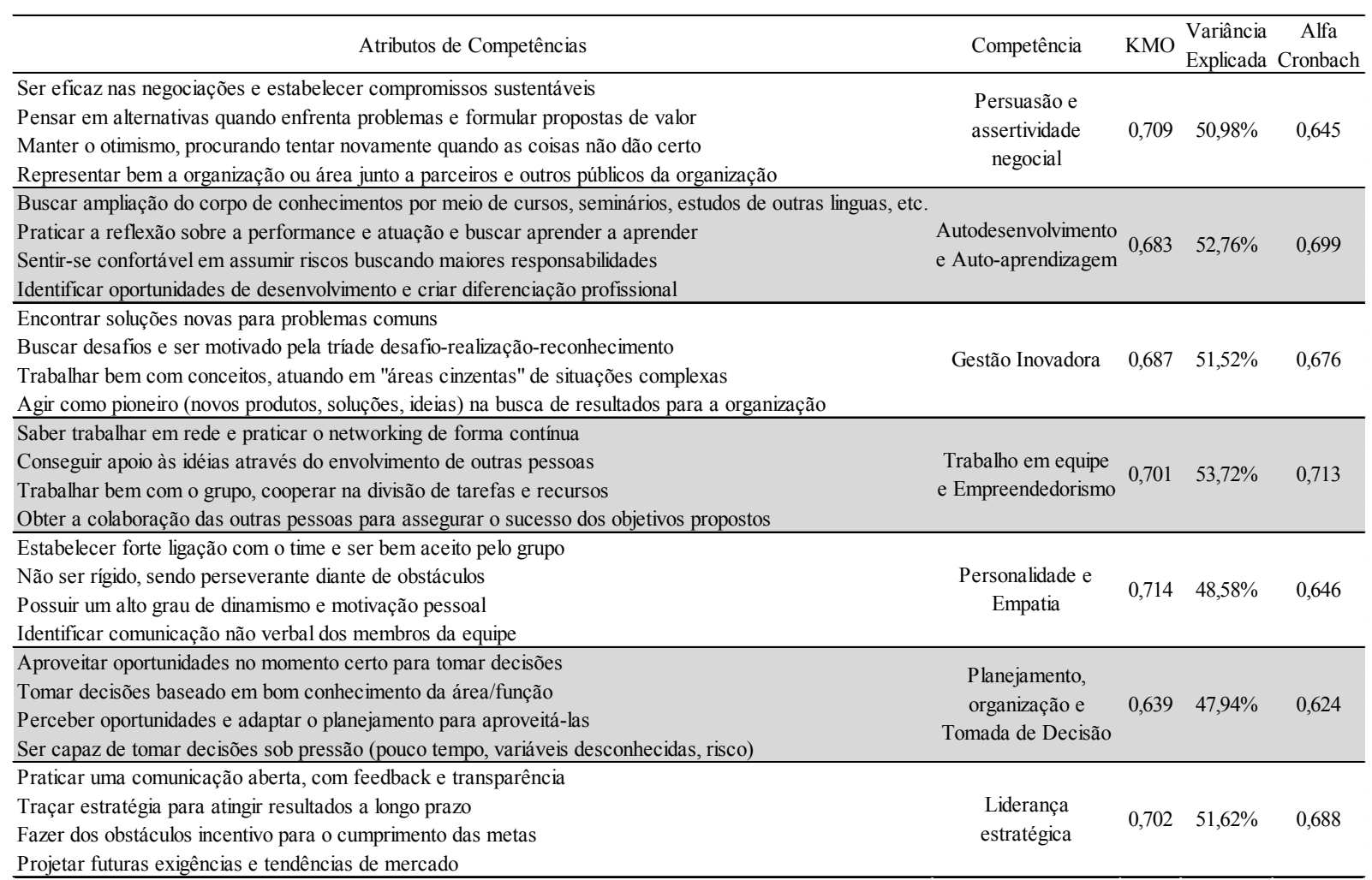

Fonte: o autor, 2013.

Os resultados indicam não haver normalidade da distribuição dos dados para vários fatores, mesmo indicando certa homogeneidade das variâncias na maioria dos fatores. Por não haver normalidade da distribuição foi utilizado o teste não paramétrico de Mann-Whitney para análise das diferenças entre as médias.

Tabela 2 - Testes de normalidade, homogeneidade e comparativo entre médias.

\begin{tabular}{|c|c|c|c|c|c|c|c|c|c|c|}
\hline & \multirow[b]{3}{*}{ Gênero } & \multicolumn{3}{|c|}{ Teste de Normalidade } & \multicolumn{4}{|c|}{$\begin{array}{c}\text { Teste da Homoge neidade } \\
\text { da variância }\end{array}$} & \multicolumn{2}{|c|}{$\begin{array}{c}\text { Teste } \\
\text { Mann-Whitney }\end{array}$} \\
\hline & & \multicolumn{3}{|c|}{ Kolmogorov-Smirnov } & Levene & $d f 1$ & $d f 7$ & $\mathrm{Sir}$ & 7 & Asymp. Sig. \\
\hline & & Statistic & df & Sig. & Statistic & dfl & dt2 & Sig. & Z & (2-tailed) \\
\hline \multirow{2}{*}{$\begin{array}{l}\text { Persuasão e Assertividade } \\
\text { negocial }\end{array}$} & Mulher &, 122 & 49 & ,068 & \multirow{2}{*}{,446 } & \multirow{2}{*}{1} & \multirow{2}{*}{128} & \multirow{2}{*}{, 505} & \multirow{2}{*}{$-2,638$} & \multirow{2}{*}{,008 } \\
\hline & Homem & ,148 & 81 &, 000 & & & & & & \\
\hline \multirow{2}{*}{$\begin{array}{l}\text { Autodesenvolvimento e } \\
\text { Auto-aprendizagem }\end{array}$} & Mulher & ,093 & 49 & $200^{*}$ & \multirow{2}{*}{890} & \multirow{2}{*}{1} & \multirow{2}{*}{128} & \multirow{2}{*}{, 347} & \multirow{2}{*}{$-1,976$} & \multirow{2}{*}{, 048} \\
\hline & Homem &, 105 & 81 &, 027 & & & & & & \\
\hline \multirow{2}{*}{ Gestão Inovadora } & Mulher & ,078 & 49 & $200^{*}$ & \multirow{2}{*}{9,157} & \multirow{2}{*}{1} & \multirow{2}{*}{128} & \multirow{2}{*}{, 003} & \multirow{2}{*}{,- 533} & \multirow{2}{*}{, 594} \\
\hline & Homem &, 081 & 81 & $200^{*}$ & & & & & & \\
\hline \multirow{2}{*}{$\begin{array}{l}\text { Trabalho em equipe e } \\
\text { Empreendedorismo }\end{array}$} & Mulher & ,136 & 49 & 023 & \multirow{2}{*}{,991 } & \multirow{2}{*}{1} & \multirow{2}{*}{128} & \multirow{2}{*}{, 321} & \multirow{2}{*}{$-3,479$} & \multirow{2}{*}{, 001} \\
\hline & Homem &, 118 & 81 &, 007 & & & & & & \\
\hline \multirow{2}{*}{ Personalidade e Empatia } & Mulher &, 133 & 49 & 029 & \multirow{2}{*}{2,303} & 1 & 128 & & -1.726 & 084 \\
\hline & Homem &, 170 & 81 &, 000 & & 1 & 120 & , & $-1,120$ & , \\
\hline Planejamento, & Mulher & ,179 & 49 &, 000 & 6190 & 1 & 128 & 014 & -2743 & 006 \\
\hline Organização e Tomada de & Homem &, 084 & 81 & $200^{*}$ & 0,190 & 1 & 128 & , 014 & $-2, / 43$ & ,006 \\
\hline Lideranca estratégica & Mulher & ,094 & 49 &, 046 & 003 & 1 & 128 & 960 & $-3,052$ & .002 \\
\hline & Homem & ,128 & 81 &, 000 & & & & & & \\
\hline
\end{tabular}

Fonte: o autor, 2013. *. Este é um limite inferior do verdadeiro significado. 
$\mathrm{Na}$ Tabela 2 são identificadas diferenças estatisticamente significativas em cinco competências: "Persuasão e Assertividade Negocial", "Autodesenvolvimento e Autoaprendizagem", "Trabalho em equipe e Empreendedorismo", "Planejamento, organização e Tomada de Decisão" e "Liderança estratégica". Os dados da Tabela 2 indicam haver diferenças estatisticamente significativas entre as percepções de homens e mulheres quanto ao construto competências gerenciais.

Foi realizada análise de correlação entre as variáveis idade, experiência profissional, experiência gerencial e as respectivas relações com cada um dos fatores do constructo competências gerenciais. Foram utilizados os escores dos fatores construídos com base nos atributos de competências e aplicado o teste não paramétrico de Spearman, conforme dados apresentados na Tabela 3. Pode-se observar haver correlação entre a variável gênero e 5 das 7 competências, confirmando os dados apresentados na análise das diferenças entre as médias de homens e mulheres.

Tabela 3 - Dados da análise de correlação

\begin{tabular}{|c|c|c|c|c|c|}
\hline Fatores & $\begin{array}{c}\text { Coeficiente de } \\
\text { Correlação } \\
\text { de Sperman }\end{array}$ & Gênero & Idade & $\begin{array}{c}\text { Experiência } \\
\text { Funcional } \\
\text { (anos) }\end{array}$ & $\begin{array}{c}\text { Experiência } \\
\text { Gerencial } \\
\text { (anos) }\end{array}$ \\
\hline \multirow{2}{*}{ Persuasão e assertividade negocial } & &,$- 232^{* *}$ &,- 134 & ,062 &,- 125 \\
\hline & Sig. &, 008 &, 127 & ,482 &, 164 \\
\hline \multirow{2}{*}{ Autodesenvolvimento e Auto-aprendizagem } & &,$- 174^{*}$ &,- 060 & 093 &,- 039 \\
\hline & Sig. & ,048 &, 498 & ,293 & ,666 \\
\hline \multirow{2}{*}{ Gestão Inovadora } & &,- 047 &,- 036 &,$- 216^{*}$ &,- 057 \\
\hline & Sig. &, 596 & 687 &, 014 &, 526 \\
\hline \multirow{2}{*}{ Trabalho em equipe e Empreendedorismo } & &,$- 306^{* *}$ &,- 133 & ,101 &,- 117 \\
\hline & Sig. &, 000 & ,131 & ,255 & ,194 \\
\hline \multirow{2}{*}{ Personalidade e Empatia } & &,- 152 &,- 077 &,- 014 &,- 061 \\
\hline & Sig. &, 084 & ,384 &, 877 &, 502 \\
\hline \multirow{2}{*}{ Planejamento, organização e Tomada de Decisão } & &,$- 242^{* \star}$ &,- 119 & ,018 &,- 041 \\
\hline & Sig. &, 006 & ,179 & ,835 & ,647 \\
\hline \multirow{2}{*}{ Liderança estratégica } & &,$- 269^{* *}$ &,- 068 &,- 036 &,- 011 \\
\hline & Sig. &, 002 &, 439 & ,683 &, 902 \\
\hline
\end{tabular}

Fonte: o autor, 2013. *valores significativos $p<.05 ;{ }^{* *}$ valores muito significativos $p<.01$

Por outro lado, pode-se indicar que a variável idade não se apresenta significativamente correlacionada com o constructo "competências gerenciais" a um nível de significância de 0,05 em nenhum de seus fatores.

A existência de correlação a um nível de significância de 0,05 aparece entre a variável Experiência Funcional e um único fator "Gestão Inovadora" indicando um grau de correlação negativa entre a variação da experiência funcional e a percepção a respeito da competência Gestão Inovadora. Este resultado indica que uma variação no tempo de experiência funcional implica uma variação negativa na percepção sobre a competência Gestão Inovadora. Buscando aumentar a capacidade explicativa dos resultados, foi analisada uma possível correlação entre experiência gerencial e percepção de competência. Os resultados indicam que a variável experiência gerencial não se apresenta significativamente correlacionada (significância e 0,05) ao constructo "competências gerenciais" em nenhum dos seus fatores.

Este resultado parece conflitante com o modelo proposto por Kolb (1997) em que o processo 
da aprendizagem e a colocação na prática destes aprendizados é um ciclo contínuo de busca pela competência. A aprendizagem constitui-se num processo em que o conhecimento é criado por meio da experiência. Porém, conforme indicação de Winterton e Winterton (1999) o processo cíclico de aprendizagem e desenvolvimento depende muito mais da riqueza e variedade das experiências vividas, do poder de reflexão e concepção de conceitos do que do tempo de atuação em uma determinada área. Outra possível explicação para estes resultados pode estar relacionada à modelagem desta investigação. Tendo em vista que esta investigação buscou medir a percepção de competência gerencial (algo genérico e abstrato) e não a auto-percepção, de quão competente cada individuo se percebe em cada atributo (algo individual e concreto) este fato pode ter influenciado as respostas do público pesquisado.

\section{Considerações finais}

Este estudo apresentou que, das sete competências identificadas após a análise fatorial, foram observadas diferenças estatisticamente significativas de percepções entre homens e mulheres em cinco delas. Conforme a Figura 5, dos 28 atributos de competências, as mulheres indicaram uma percepção média superior a dos homens em todos os atributos.

Esta descoberta corrobora com o estudo de McGregor e Tweed (2001), cujos resultados indicam que as mulheres estariam mais preocupadas com o aprimoramento de suas competências mesmo para aquelas competências que já eram percebidas como desenvolvidas.

Segundo os autores, estudos comparativos entre percepções de homens e mulheres em cargos gerenciais com respeito as suas competências revelam uma concentração das competências relacionadas à gestão de pessoas, incluindo comunicação e áreas estratégicas tanto para homens quanto mulheres. A maior diferença identificada foi quanto às competências relacionadas à gestão de orçamentos e custos mais evidente na percepção das mulheres. Da mesma forma, os estudos revelaram que as mulheres mesmo se percebendo competentes em determinadas atribuições estariam mais propensas a buscar aprimoramentos de suas competências quando comparadas aos homens. Os autores sugerem que uma possível resposta à interpretação das diferenças seria a necessidade das mulheres de demonstrarem suas competências de forma superior aos homens para obterem reconhecimento o que vai ao encontro do que afirma Marshall (1995) quanto à masculinização feminina no ambiente organizacional.

Figura 5 - Comparativo da Percepção de Mulheres e Homens quanto aos atributos de competências gerenciais.

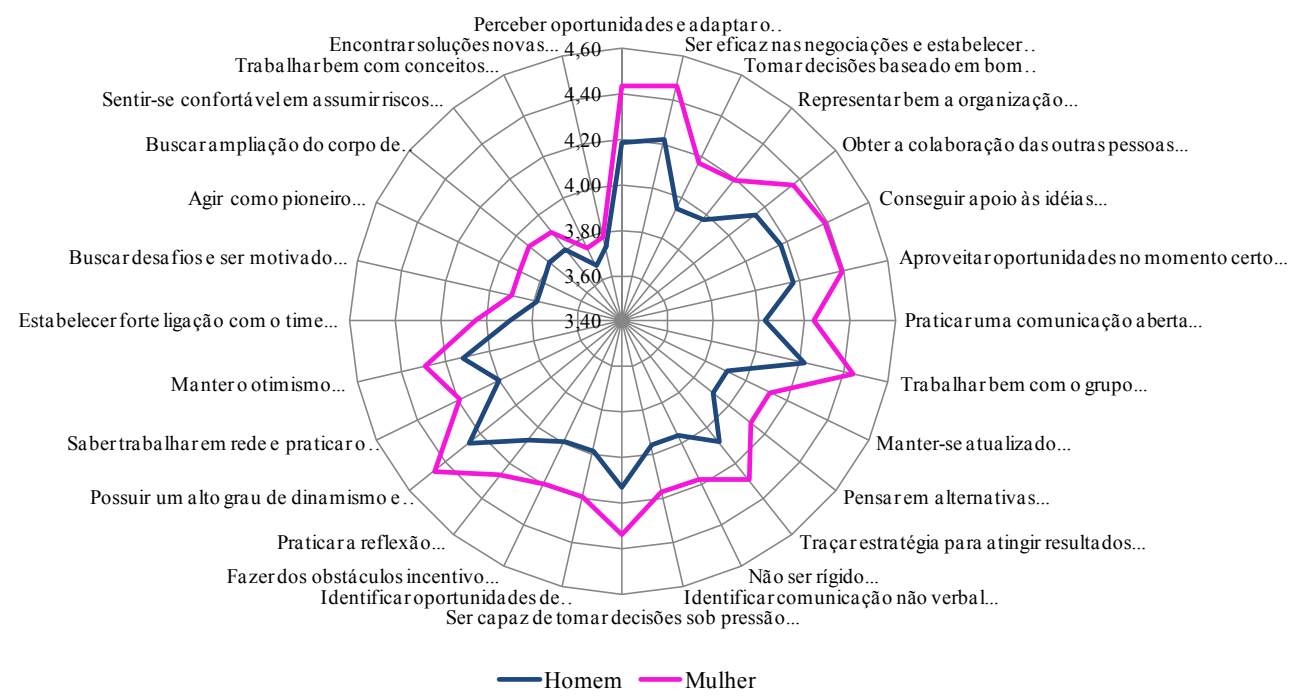

Fonte: o autor, 2013. 
Segundo Marshall (1995), apesar de ações de igualdade de oportunidades e de exemplos de mulheres atuando em cargos gerenciais, pouco se alterou em termos de modelos e estilos de liderança aceitos, modelos de carreira e de práticas do trabalho. Permanece um formato "masculinizado" anteriormente definido para homens e que as mulheres ainda são forçadas a se adaptar a estas normas organizacionais. Porém, na visão da autora, em busca de vantagens competitivas e da maximização do retorno sobre os recursos humanos, as organizações deveriam iniciar um processo de transformação dos padrões da cultura organizacional considerando o aspecto das diferenças entre gênero. A literatura sobre o desenvolvimento das mulheres indica a necessidade de um debate amplo em um mundo inteiramente dominado por homens, em que os significados para as mulheres precisam ser compreendidos e valorizados. Todavia, Marshall (1995) indica haver mulheres e homens que estão prontos para o diálogo mais aberto, que querem se envolver, sem disfarce, com questões fundamentais de gênero e desigualdade. Segundo a autora, este é o momento de correr alguns riscos rompendo silêncios e buscando o propósito principal que reside na potencial reconceitualização e na possível mudança das organizações.

A contribuição desta investigação está na identificação na amostra pesquisada de que homens e mulheres percebem os atributos de competências de maneiras diferentes. Ao revelar que entre as variáveis demográficas pesquisadas, é a variável gênero que mais se correlaciona com a percepção sobre o constructo competências gerencial quando comparada às variáveis idade, experiência profissional e experiência gerencial abre caminho para novos debates sobre questões de gênero nas organizações. Alguns questionamentos que podem ser feitos seriam com respeito às diversas ferramentas e modelos de competência que estão sendo trabalhados nas organizações. Estariam tais modelos enviesados em sua construção por não consideraram haver diferenças de percepções entre os gêneros? Dever-se-ia adicionar a questão do gênero à indicação de Gramigna (2007) sobre as dificuldades quanto ao uso de modelos de gestão por competências?

Partindo das considerações de Brandão e Guimarães (2001) de que, pela complementaridade e interdependência seria necessária a integração em um único modelo de gestão as atividades de planejamento, acompanhamento e avaliação de desempenho, a partir de um diagnóstico das competências da organização, se homens e mulheres possuem percepções diferentes sobre as competências gerenciais, o gênero do avaliador introduziria uma variável a mais no processo podendo resultar em feedback, sugestões de correção de rumo e trilhas de aprendizagem diferentes para o desenvolvimento das pessoas na organização.

A realização de estudos que identifiquem diferenças entre mulheres e homens pode permitir a compreensão e a articulação desse diferentes significados. Mulheres em cargos gerenciais podem até ser vistas como estando em estágios iniciais de aceitação como membro da organização, porém devem ter persistência na reflexão e abertura às discussões, em revelar suas intenções e suposições assim como na construção do processo de sensemaking entre homens e mulheres.

Como limitações do estudo, pode-se indicar que o número de respondentes não propiciou uma análise fatorial robusta com todos os 36 itens de atributos de competências, pois para isso seria necessária uma amostra de pelo menos 180 respondentes (HAIR, 2006). A decisão de se avaliar os 36 atributos independentes dos fatores previamente definidos por Cardoso (2009) buscou minimizar esta limitação. Além disso, os julgamentos realizados pelos participantes da pesquisa não podem ser considerados indicadores confiáveis da expressão de competências no trabalho, pois por serem percepções contém subjetividade e imprecisões, assim como podem incorrer em erros de halo e outros vieses. Acredita-se que essas limitações potenciais, embora possam restringir os resultados, em nada invalidam o 
estudo, considerando seu caráter exploratório. Como contribuição final, este estudo propõe uma ferramenta composta por 7 competências e 28 atributos que pode ser considerada um modelo parcimonioso para mensuração do constructo competências gerenciais. A partir da escala final, obtida pela análise fatorial e o reagrupamento dos itens, abrem-se oportunidades para usar o instrumento em estudos futuros com a possibilidade de comparar as respostas com os resultados aqui obtidos. 


\section{Referências Bibliográficas}

BOYATZIS, R. E. (1982). The competent manager. New York: John Wiley \& Sons. CARBONE, P.P. (2006). Gestão por competências e gestão do conhecimento. Rio de Janeiro: Editora FGV.

BRANDÃO, H. P.; GUIMARÃES, T. A. Gestão de desempenho: tecnologias distintas ou instrumentos de um mesmo construto? Revista de Administração de Empresas, vol. 41, $n^{\circ} 1$, p. 8 -15. Jan./Mar. 2001.

CARDOSO, A. L. J. (2009). Percepções de Gestores sobre Competências Gerenciais em diferentes Contextos: Estabilidade e Mudança Organizacional. REBRAE. Revista Brasileira de Estratégia (Impresso), v. 2, pp. 147-169.

CHEETHAM, G.; CHIVERS, G. (1996). Towards a holistic model of professional competence. Journal of European Industrial Training.

(1998). The reflective (and competent) practitioner: a model of professional competence which seeks to harmonise the reflective practitioner and competence-based approaches. Journal of European Industrial Training.

DRUCKER, P. O advento da nova organização. In: Harvard Business Review. Gestão do conhecimento. Rio de Janeiro: Campus, 2001.

DUTRA, J. S. (2001). (org.) Gestão por competências. São Paulo: Gente.

FIELD, A. (2009). Descobrindo a estatística usando o SPSS. 2 ed. Porto Alegre. Artmed.

FREITAS, I. A. Trilhas de desenvolvimento profissional: da teoria à prática. In: ENCONTRO DAASSOCIAÇÃO NACIONAL DOS PROGRAMAS DE PÓS-GRADUAÇÃO EM ADMINISTRAÇÃO, 26, 2002, Salvador. Anais... Salvador: ENANPAD, 2002.

; BRANDÃO, H. P. Trilhas de aprendizagem como estratégia para desenvolvimento de competências. In: ENCONTRO DA ASSOCIAÇÃO NACIONAL DOS PROGRAMAS DE PÓSGRADUAÇÃO EM ADMINISTRAÇÃO, 29, 2005, Brasília. Anais... Brasília: ENANPAD, 2005.

GRAMIGNA, M.R. Modelo de competências e gestão dos talentos. São Paulo: Makron Books, $2^{\mathrm{a}}$ edição. 2007.

HAIR, Jr. (2006). Análise Multivariada de dados. Porto Alegre: Bookman.

KOLB, D. A. (1997). A gestão e o processo de aprendizagem. In: STARKEY, K. (org.) Como as organizações aprendem - relatos do sucesso das grandes empresas. São Paulo: Futura, pp. 321-341.

Le BOTERF, G. (1999). Competénce et navigation profissionnelle. Paris: Éditions d'Organisatio, (2003). Desenvolvendo a competência dos profissionais. Porto Alegre: Artmed.

MARSHALL, J. (1995). Researching women and leadership: some comments on challenges and opportunities. International Review of Women and Leadership. v.1, n.1, pp. 1-10.

McLAGAN, P.A. (1997). “Competencies”, Training and Development. American Society for Training and Development, v. 51, n. 5, may, pp. 40-47.

McCLELLAND, D. C. (1973). Testing for Competence rather than Intelligence. American Psychologist. v. 28, n. 1.

McGREGOR, J.; TWEED, D. (2001). Facing the challenge of improving managerial competence in small business: The New Zealand experience. 31st European Small Business Seminar. Dublin, Ireland. 
ROBOTHAM, D.; JUBB, R. (1996). Competences: measuring the unmeasurable. Management Development Review. Bradford, v.9, n. 5.

RUAS, R. (2005). Gestão por competências: uma contribuição à estratégia das organizações. In: RUAS, R., ANTONELLO, C. S., BOFF, L. H. (orgs.) Aprendizagem organizacional e competências. Porto Alegre : Bookman.

ZARIFIAN, P. (1999). Objective Competence. Liasson, Paris. 